\title{
"Assessment of the social influence and facilitating conditions that support nurses' adoption of hospital electronic information management systems (HEIMS) in Ghana using the unified theory of acceptance and use of technology (UTAUT) model"
}

\author{
Lu Lin Zhou ${ }^{1}$, Joseph Owusu-Marfo ${ }^{1,2^{*}} \mathbb{D}$, Henry Asante Antwi ${ }^{1}$, Maxwell Opuni Antwi ${ }^{1}$,
} Arielle Doris Tetgoum Kachie ${ }^{1}$ and Sabina Ampon-Wireko ${ }^{1}$

\begin{abstract}
Background: Hospital electronic information management systems (HEIMS) are widely used in Ghana, and hence its performance must be carefully assessed. Nurses as clinical health personnel are the largest cluster of hospital staff and are the pillar of healthcare delivery. Therefore, they play a crucial role in the adoption and assessment of HEIMSs in Ghana. This report sought to assess the "Social Influence" (SI) and "Facilitating Conditions" (FC) that support Nurses' Acceptance of HEIMS in Ghana using the "Unified Theory of Acceptance and Use of Technology" (UTAUT) model.

Methods: This study applied a non-experimental survey design. An electronic platform questionnaire on smartphones was used to collect data on 660 nurses. Statistically, AMOS Structural Equation Modelling (SEM) version 22.0 was employed to examine the research model.
\end{abstract}

Results: "Behavioral Intention" (BI) to HEIMS use was significantly predicted by SI and FC $(p<0.001)$. Notably, both $\mathrm{SI}$ and FC had an influence on nurses' use behavior (UB) with behavioral intention (BI) as the mediator, which explains a total of $42.1 \%$ variance in the intention of nurses to use HEIMS. Likewise, UB of HEIMS was also significantly predicted by $S I\left(R^{2}=43.2\right)$ and $B I\left(R^{2}=0.39 .6\right)$ with both constructs explaining a total of $51.7 \%$ of the variance in nurses' acceptance to use HEIMS.

Conclusion: Nurses' adoption of HEIMS in terms of the UB was influenced by SI and BI, whiles SI and FC had the strongest influence on BI (serving as mediator) of UB to adopt and use HEIMS among the nurses in Ghanaian hospitals.

Keywords: Social influence, Facilitating conditions, Health information management, Hospital information systems, Health technology, Electronic health/medical records, Nurses, Ghana

\footnotetext{
* Correspondence: 5103170254@stmail.ujs.edu.cn

${ }^{1}$ Center for Medical Insurance, Hospital Management and Health Policy

Research, School of Management, Jiangsu University, 301 Xuefu Road,

Zhenjiang, Jiangsu 212013, People's Republic of China

2Department of Health Informatics/Health Information Management, College

of Health and Well-Being, Kintampo Bono East, Ghana
}

(c) The Author(s). 2019 Open Access This article is distributed under the terms of the Creative Commons Attribution 4.0 International License (http://creativecommons.org/licenses/by/4.0/), which permits unrestricted use, distribution, and reproduction in any medium, provided you give appropriate credit to the original author(s) and the source, provide a link to the Creative Commons license, and indicate if changes were made. The Creative Commons Public Domain Dedication waiver (http://creativecommons.org/publicdomain/zero/1.0/) applies to the data made available in this article, unless otherwise stated. 


\section{Background}

Health care organizations around the world continue to invest in health information technologies (HITs) $[1,2]$. However, it has been recognized that user acceptance is one of the urgent issues in the implementation and the management of HITs [2]. Ghanaian Nurses work at the frontline of the healthcare system in the country with access to vital records about the patient populace in Ghanaian hospitals, hence, their usage assessment is necessary. Hospitals have invested considerable assets to enhance information technology (IT) infrastructure and set up medical institution record systems to enhance medical nursing care, administration efficiency and effectiveness as well as meet the challenges of an increasing number of the competitive enterprise environment and altering healthcare policies [3]. Nursing care is primarily based on a procedure that entails assessment, diagnosis, effects and planning, implementation, as well as assessment of the care of the affected person, while the documentation in the health report ought to mirror this system [4]. Besides, these nursing services are emerging field that has been substantially influenced by health technology usage. In this regard, some knowledge of technology/computing literacy is, therefore prerequisite for a nursing career in many healthcare centres. It is reported that healthcare providers like nurses are established to resist technology [5]. Pertinently, the successful implementation of any mHealth and electronic health records (EHRs) critically depends on user acceptance [6]. The EHRs seeks to allow the execution of patientcare-related health facility functions, which consists of patient administration, medical institution monetary affairs, and legal affairs, amongst different issues. Actually, EHRs is an integrated records system that performs a key function in supporting medical institution affairs via the use of suitable healthcare IT. This report aims; 1 . to determine the social influence of Nurses and its impact on usage behavior of hospital electronic information management systems (HEIMS). 2. to assess the facilitating conditions of the hospitals and behavioral intentions (A user's readiness to carry out a particular behavior) of Nurses that have an influence on usage behavior of HEIMS. The hypotheses were as follows;

H1: Social influence (SI) (moderators; professional experience; gender; age and voluntariness) will positively influence on behavioral intentions (BI) to use HEIMS, H2: SI will have a direct influence on usage behavior (UB)., H3: Facilitating conditions (FC) (moderators; professional experience; gender; age and voluntariness) will have a significant influence on BI., H4: FC will have a direct positive influence on UB and H5: BI will have a significant positive influence on usage. In this report, all health information technologies and EHRs platforms are termed as "Hospital Electronic Information Management
Systems" (HEIMS). This report assesses Nurses' acceptance of the adoption of "Hospital Electronic Information Management Systems" (HEIMS) via application of the UTAUT model [7]. The reason for using nurses as the study population is because they work at the frontline of the clinical healthcare system in Ghana with access to essential patient data in Ghanaian hospitals [8].

\section{"The unified theory of acceptance and use of technology (UTAUT) Model"}

The proposed UTAUT model was validated appropriately to provide a unified theoretical groundwork for the promotion of research on information systems (IS) or adoption of IT and dissemination. Four (4) core parameters suggested by this model to directly determine health IT behavioral intentions and use behavior include performance expectancy, effort expectancy, social influence and facilitating conditions [7]. Additionally, the model assumed that the factors such as age, gender, experience and voluntariness to use greatly moderate the effect of key parameters [7]. The concept of UTAUT was developed via review, integration and mapping of eight dominant theories and models comprising; 1. "The Theory of Reasoned Action (TRA)", 2. "the Technology Acceptance Model (TAM)", 3. "the Motivational Model (MM)", 4. "the Theory of Planned Behavior (TPB)", 5. "a blended Theory of Planned Behavior/Technology Acceptance Model (CTPB-TAM)", 6. "the Model of PC Utilization (MPCU)", 7. "the Innovation Diffusion Theory (IDT)", and 8. "the Social Cognitive Theory (SCT)". These models and theories have been efficaciously utilized through a variety of previous studies [7-10] on technology or adoption of innovation as well as circulation within both the ISs area and different disciplines including marketing, social health, psychology, and management science. Based on the argument that several of the concepts of the current theories are naturally comparable, UTAUT was motivationally defined and validated. In this context, it was, therefore, logical to map out and bring the various concept together and create a merged theoretical basis [7, 11, 12]. The proposed conceptual model adopted from the UTAUT model by [7] is depicted in (Fig. 1).

\section{Methods}

Research study design, settings and participants

This study applied descriptive non-experimental survey study design. The research was conducted from January 15th to February 28th, 2019. This design was adopted in the present study because the researchers intended to assess the nurses use behavior of HEIMS at a point in time. This study focused on primary data derived from Nurses working in five major public hospitals in Ghana where HEIMS was being applied for patient care. All the Nurses who attended to patients care at the aforementioned 


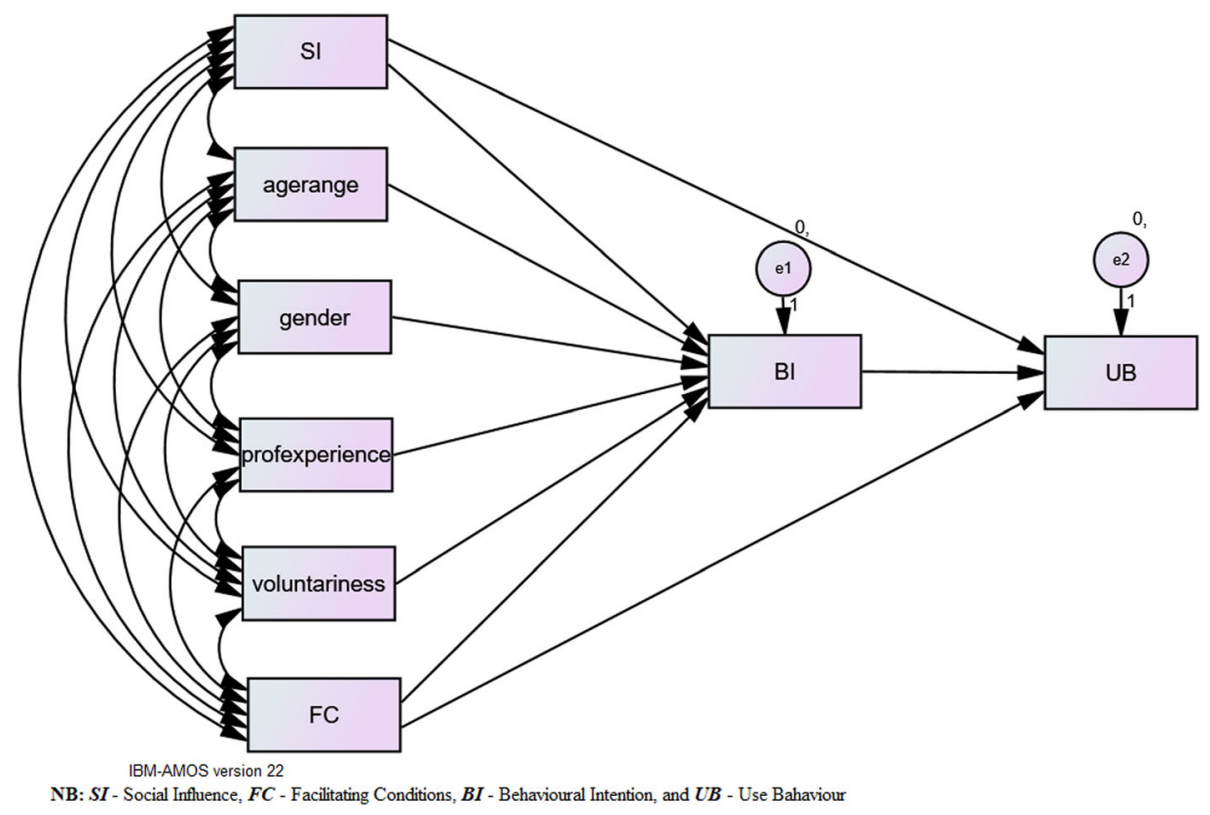

Fig. 1 Conceptual Model

hospitals qualified to participate in this study. Privately owned hospitals were excluded because they did not form part of the government's EHRs (HEIMS) implementation plan at the time this study was conducted. A purposive sampling approach was used to select five public hospitals comprising of 3 teaching and 2 regional hospitals that use HEIMS in Ghana. Simple random sampling method was then used to recruit 660 nurses from the selected five government-owned hospitals.

\section{Research instrument}

Numerical responses (form the Likert rating scale) were used in this survey via an electronic questionnaire to gather data from the respondents. Through preliminary study, UTAUT tool was established to be good enough for application in a cross-cultural investigation, like research involving participants from outside its original country of origin [13]. The UTAUT tool (particularly the original English version) was modified to fit the objectives of the present study [14]. The UTAUT constructs-related items in the questionnaire were ascertain using a 1 to 7 -point Likert rating scale which ranged from "Strongly disagree (1)" to "Strongly agree (7)" for SI, FC and BI. Likewise, usage behavior was evaluated through a 1 to 8 -point Likert rating scale that ranged from "Have not used (1)" to "Almost every day (8)". Notably, extra information like age, gender, experience and voluntariness of use was obtained from the respondents using the questionnaire to serve as the moderators. The moderators were treated as categorical data for the analysis.

\section{Data collection procedure and statistical analysis}

Data was collected using an organized questionnaire composing of items based on constructs validated in the original English version of the UTAUT model as described elsewhere [7]. An electronic data was obtained (via smart mobile phones and tablets) with structured questionnaire coded in Open Data Kit (ODK) application [15]. The questionnaire was pre-tested severally before being sent out for the data collection. The feedback of the pre-testing prompted the authors to make minor modifications to suit the study settings. The modified survey questions were tested for validity, reliability and accuracy. Almost all the selected nurses were approached during their working shifts and were contacted either through a mobile phone or verbally to take part in this study. The electronic questionnaire (made with ODK mobile application) were distributed to the nurses personally by the authors and other supporting data collectors. Completed questionnaires were automatically sent to our ODK google aggregate server-based website (www.odkproject-1333. appspot.com). All the questions were written in understandable English language and each questionnaire took about 4-10 min to complete. The questionnaire composed of forty-two questions including demographics.

Parameters were measured indirectly through indicators designed to elicit responses associated with a variable [16]. Most researchers use Structural Equation Modelling (SEM) as a measurement statistical tool for analysing data [17]. Statistically, SEM (IBM AMOS version 22.0) was employed to analyze the data that were collected. Actually, SEM is a multivariate approach that 
combines multiple regression factors and component analysis $[16,18]$. In SEM evaluation, a causality network is estimated by researchers with respect to a theoretical model [19]. The main UTAUT study reported using the "partial least square" (PLS) path modeling approach [7] as having negligible demands on sampling size, residual or underlying data distributions, and measurement scales. Reliability is associated with the measurement within parameters which is independent of the state within other variables, while construct validity is associated with the measurement within parameters $[20,21]$. The assessment of the "internal consistency reliability" (ICR) of parameters such as, "Cronbach's alpha" (CA) was applied to examine the one-dimensionality of a group of the survey questionnaire measurements. Moreover, additional analysis such as "average variance extracted" (AVE) and "Composite reliability" (CR) for the individual construct provides coefficients which confirmed the reliability of the survey [22]. In this regard, $0.70,0.70$ and 0.50 were estimated as the respective recommended values [23]. The linear correlation coefficient $\left(R^{2}\right)$ of each dependent construct in the model was generated in order to assess whether the model fit well to the hypothesized relationship [24]. Notably, $R^{2}$ is interpreted as the proportion of explained variance similar to regression analysis and therefore denotes the percentage of variance in the dependent constructs that is explained with the independent ones [25].

\section{Reliability and validity of measurement}

The Cronbach's Alpha for testing the overall reliability for the measurement items was 0.949 , whiles the KaiserMeyer-Olkin Measure (KMO) of sampling adequacy was 0.928 . The individual constructs validity and reliability testing results are shown in Table 3 and narrated in the results section.

\section{Results}

\section{Descriptive statistics}

This survey targeted 700 participants, but 660 respondents answered the questionnaire representing a response rate of $94.3 \%$. Possibly, the innovative use of smart mobile phones might have ensured fast and easy answering of the questions, thereby resulting in a high response rate albeit participation being completely voluntary. Notably, the majority of nurses in Ghanaian hospitals are females. Hence, it was not surprising that 404 (61.2\%) of the respondents were females. The respondents' demographic data have been summarized and depicted in Table 1. Staff nurse was the most usual nursing category title among the respondents (58.4\%). Most respondents (52.4\%) were between the ages of 20 and 30 years with all the respondents having at least a diploma degree (basic qualification to become a nurse in
Table 1 Demographic Characteristics of Respondents

\begin{tabular}{|c|c|c|}
\hline Parameter & Frequency $(N=660)$ & Percentage (\%) \\
\hline \multicolumn{3}{|l|}{ 1. Age of Respondents } \\
\hline 20-30 years & 346 & 52.4 \\
\hline $31-40$ years & 251 & 38 \\
\hline $41-50$ years & 63 & 9.6 \\
\hline \multicolumn{3}{|l|}{ 2. Gender } \\
\hline Male & 256 & 38.8 \\
\hline Female & 404 & 61.2 \\
\hline \multicolumn{3}{|l|}{ 3. Professional Experience } \\
\hline $0-5$ years & 317 & 48.03 \\
\hline $6-10$ years & 163 & 24.70 \\
\hline $11-15$ years & 92 & 13.94 \\
\hline 16-20 years & 76 & 11.52 \\
\hline $21-25$ years & 12 & 1.81 \\
\hline \multicolumn{3}{|l|}{ 4. Type of Nurse } \\
\hline Staff Nurse & 386 & 58.4 \\
\hline Nursing Officer & 206 & 31.2 \\
\hline Emergency Nurse & 58 & 8.8 \\
\hline Critical Nurse & 5 & 0.8 \\
\hline Pre-Operative Nurse & 5 & 0.8 \\
\hline \multicolumn{3}{|l|}{ 5. Voluntariness } \\
\hline Completely not voluntary & 173 & 26.2 \\
\hline Not Voluntary & 328 & 49.7 \\
\hline Somewhat not voluntary & 47 & 7.1 \\
\hline Neutral & 31 & 4.7 \\
\hline Somewhat voluntary & 31 & 4.7 \\
\hline Voluntary & 43 & 6.5 \\
\hline Completely voluntary & 7 & 1.1 \\
\hline \multicolumn{3}{|l|}{ 6. Type of HEIMS used } \\
\hline LHIMS & 488 & 73.9 \\
\hline HAMS & 172 & 26.1 \\
\hline
\end{tabular}

NB: LHIMS - Lightwave Health Information Management Systems, HAMS Hospital Administration Management Systems

Ghana). A portion (48.03\%) of the respondents had over one to five years of professional experience, and almost all the nurses have had at least one year of HEIMS experience. It was observed that all the respondents used two main types of HEIMS (lightwave health information management system (LHIMS) and hospital administration management system (HAMS)) in the regional and teaching hospitals in Ghana.

\section{The measurement models}

The UTAUT model is composed of nine observed variable constructs. However, in this report, the measurement was primarily based on four of the constructs. The overall goodness of fit was assessed via some model fit 
measures. The results of the goodness of fit statistics are as follows; the Chi-square statistics $\left(X^{2}=42.78\right)$ to degrees of freedom (d.f. $=4)$ for the measured model [26]. The values of GFI (0.98), CFI (0.98), NFI (0.98), NNFI (0.96), and IFI (0.98) were greater-than 0.9 benchmark [26]. Likewise, the RMSEA was 0.06, which was within the acceptable levels of 0.05-0.08 [26]. As shown earlier, the required criteria for the majority of the fit indices were met as proposed by Hair et al. [26]. This result represents a reasonable fit between the obtained data and the suggested model measurement. In view of this, the instrument's psychometric properties were evaluated regarding the "discriminant validity" (DV), "convergent validity" (CV) and reliability. The findings of the items' loadings, means and the CA for all the measurement items (when an item is deleted) statistics are presented in Table 2.

Likewise, Table 3 displays the results of variances, CA, $\mathrm{CR}, \mathrm{AVE}$ and DV as well as the Kaiser-Meyer-Olkin

Table 2 Result of Items Loading and Descriptive Statistics of Construct Measurements

\begin{tabular}{|c|c|c|c|c|}
\hline Construct Measurements & Item loading $\lambda$ & $\varepsilon$ & Mean & $\begin{array}{l}\text { Cronbach's alpha (CA) } \\
\text { (if item deleted) }\end{array}$ \\
\hline PE1 & 0.880 & 0.226 & 5.760 & .943 \\
\hline PE2 & 0.947 & 0.103 & 5.640 & .943 \\
\hline PE3 & 0.928 & 0.139 & 5.730 & .942 \\
\hline PE4 & 0.496 & 0.754 & 3.860 & .946 \\
\hline EE1 & 0.914 & 0.165 & 5.540 & .942 \\
\hline EE2 & 0.868 & 0.247 & 5.570 & .942 \\
\hline EE3 & 0.932 & 0.131 & 5.640 & .943 \\
\hline EE4 & 0.864 & 0.254 & 5.650 & .943 \\
\hline ATUT1 & 0.592 & 0.650 & 5.660 & .945 \\
\hline ATUT2 & 0.913 & 0.166 & 5.500 & .942 \\
\hline ATUT3 & 0.893 & 0.203 & 5.230 & .942 \\
\hline ATUT4 & 0.904 & 0.183 & 5.450 & .942 \\
\hline SI1 & 0.913 & 0.166 & 5.700 & .942 \\
\hline $\mathrm{SI} 2$ & 0.909 & 0.174 & 5.830 & .942 \\
\hline $\mathrm{SI} 3$ & 0.280 & 0.922 & 3.870 & .946 \\
\hline $\mathrm{S} / 4$ & 0.890 & 0.208 & 6.140 & .943 \\
\hline SE1 & 0.842 & 0.290 & 5.400 & .942 \\
\hline SE2 & 0.667 & 0.555 & 5.830 & .944 \\
\hline SE3 & 0.904 & 0.182 & 5.150 & .942 \\
\hline SE4 & 0.811 & 0.343 & 5.120 & .943 \\
\hline FC1 & 0.550 & 0.698 & 5.530 & .943 \\
\hline FC2 & 0.691 & 0.523 & 5.100 & .943 \\
\hline FC3 & 0.843 & 0.289 & 2.900 & .946 \\
\hline FC4 & 0.833 & 0.306 & 2.890 & .947 \\
\hline ANX1 & 0.402 & 0.838 & 5.020 & .943 \\
\hline ANX2 & 0.860 & 0.260 & 3.800 & .948 \\
\hline ANX3 & 0.886 & 0.215 & 3.610 & .948 \\
\hline ANX4 & 0.830 & 0.311 & 4.130 & .947 \\
\hline Bl1 & 0.985 & 0.030 & 5.590 & .942 \\
\hline $\mathrm{B} 12$ & 0.976 & 0.047 & 5.610 & .942 \\
\hline $\mathrm{Bl} 3$ & 0.980 & 0.040 & 5.580 & .942 \\
\hline $\mathrm{B} \mid 4$ & 0.945 & 0.107 & 5.550 & .943 \\
\hline UB1 & 0.949 & 0.099 & 7.820 & .944 \\
\hline UB2 & 0.949 & 0.099 & 4.370 & .942 \\
\hline
\end{tabular}

NB: $\lambda$ - factor loadings values, $\varepsilon$ - error of the construct measurements values. SI - Social Influence, FC - Facilitating Conditions, BI - Behavioral Intention, and UB - Use Behavior 
Table 3 Measurement Model; Results of AVE (Convergent Validity), CR, CA (Reliability Testing) and KMO (Sampling Adequacy Test)

\begin{tabular}{llllllll}
\hline Constructs & Mean & S. Dev. & Variance & AVE & CR & CA & KMO \\
\hline PE & 5.248 & 1.046 & 1.095 & 0.695 & 0.896 & 0.779 & 0.754 \\
EE & 5.600 & 0.934 & 0.873 & 0.801 & 0.941 & 0.915 & 0.802 \\
ATUT & 5.460 & 1.062 & 1.128 & 0.700 & 0.901 & 0.831 & 0.785 \\
SI & 5.386 & 1.078 & 1.163 & 0.633 & 0.859 & 0.709 & 0.745 \\
SE & 5.378 & 1.026 & 1.053 & 0.657 & 0.884 & 0.824 & 0.760 \\
FC & 4.105 & 1.183 & 1.399 & 0.546 & 0.824 & 0.723 & 0.564 \\
ANX & 4.140 & 1.256 & 1.577 & 0.594 & 0.845 & 0.753 & 0.708 \\
BI & 5.583 & 1.195 & 1.429 & 0.944 & 0.985 & 0.980 & 0.873 \\
UB & 6.094 & 1.978 & 3.912 & 0.901 & 0.948 & 0.842 & 0.560 \\
\hline
\end{tabular}

NB: $\boldsymbol{A V E}$ - Average Variance Extracted, $\boldsymbol{C} \boldsymbol{R}$ - Composite Reliability, CA Cronbach's Alpha, KMO - Kaiser-Meyer-Olkin and S. Dev - Standard Deviation. SI - Social Influence, FC - Facilitating Conditions, BI - Behavioral Intention and UB - Use Behavior

(KMO) measure of the sampling adequacy of the constructs. The CA for all the constructs was above the 0.7 thresholds (0.709 to 0.980$)$. The assessment of the inner consistency of the measurement model was through the calculation of the CR of the constructs which ranged between 0.824 and 0.985 but exceeded the cut-off of 0.70 as recommended elsewhere [27]. In the current report, the construct validity was measured in terms of the usage of AVE and DV. Fornell and Larcker [28] proposed that the common AVE number exceeds 0.5 and is larger than every square correlation with recommended sufficient CV and DV. From Table 3 it could be observed that the AVE of the measurements ranged from
0.546 to 0.944 , which surpassed the endorsed value (AVE > 0.5) [28]. This indicated a remarkable CV which is considered as one key criterion for acceptable DV [27]. Besides, it was discovered that all the AVE values were larger than every squared correlation coefficient, demonstrating the exact DV as indicated in Table 3 (the square root of AVE) and was proven with the aid of previous study [27]. The data obtained in this study had adequate $\mathrm{CA}, \mathrm{CR}$ and DV. The sampling adequacy (KMO) of all the constructs were also higher than 0.5 .

\section{The structural model}

The structural model was examined via SEM technique with the effects of three latent variables tested. From Table 6; SI (age, prof. Experience, gender, and voluntariness acted as moderators) was explained by a variance of $40.1 \%\left(R^{2}=0.401\right)$, while FC (moderated by age, prof. Experience, gender, and voluntariness) with just $24.8 \%$ $\left(R^{2}=0.248\right)$, and the model was wholly explained by a variance of $42.1 \%$ of $\mathrm{BI}$ (as mediator) to use HEIMS. In terms of usage behavior of HEIMS, SI and FC explained 43.2 and $14 \%$ of the variance respectively with BI explaining $39.6 \%$ of the variance while a total explained variance was $51.7 \%$. Fig. 2 shows the standardized path coefficients which signify the substantial structural association within the tested parameters. The data showed that FC had no direct significant influence $(p=0.15)$ on the usage of HEIMS by the nurses, thus it did not support H4. Contrariwise, SI was shown to directly and significantly influence the usage behavior of nurses to use HEIMS $(p<0.001)$, thereby supporting H2. Furthermore, SI substantially impacted on the BI (as mediator) to use

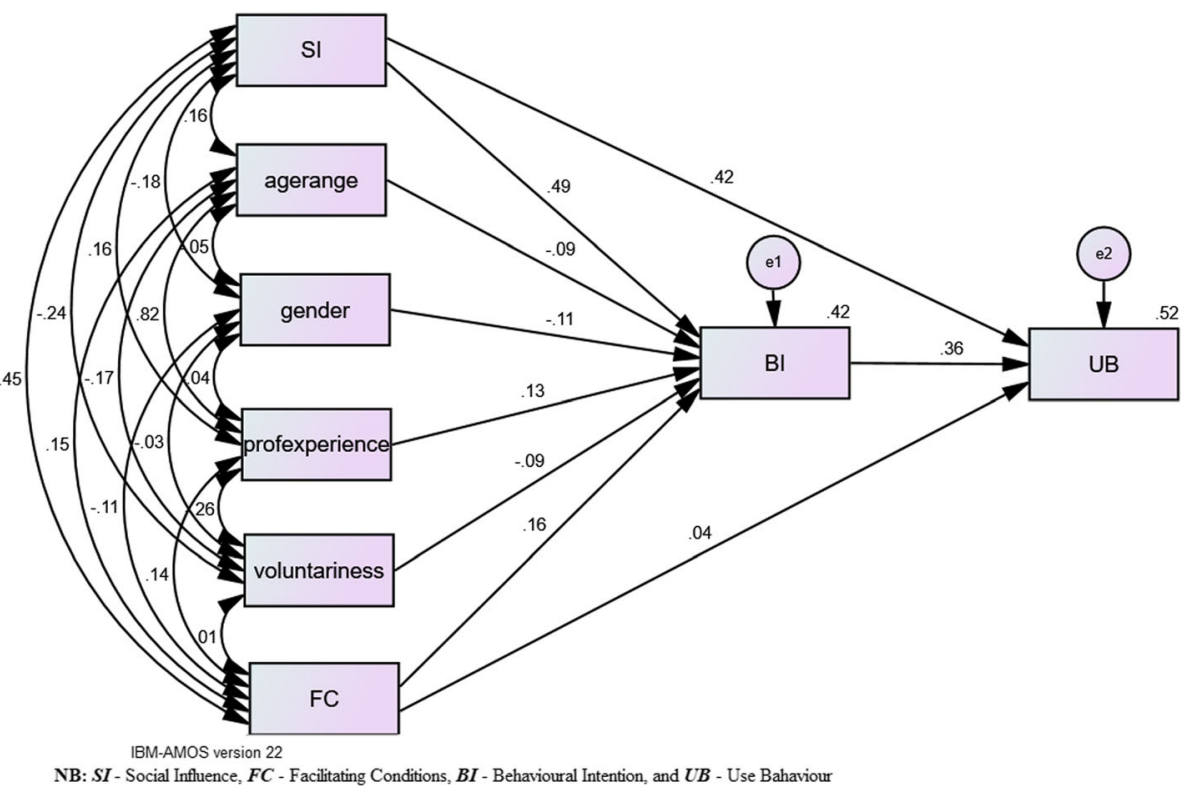

Fig. 2 Standard Values of Structural Model 
HEIMS $(p<0.001)$ and this supported H1. In addition, FC significantly influenced the usage behavior $(p<0.001)$ in a positive manner with $\mathrm{BI}$ playing the mediating role and thus, also supporting H3. Besides, BI predicted or had significance $(p<0.001)$ direct influence on UB of the nurses to use HEIMS, which also supported H5 (Table 4).

\section{Discussion}

The main findings of the current study are enumerated as follows: 1 . SI and FC with BI serving as the mediator significantly influenced the UB of nurses to adopt and use HEIMS. 2. FC had an insignificant direct influence on UB to use the system. 3. Lastly, SI directly and significantly influenced UB and the adoption of HEIMS by nurses (Table 4 and Table 5). Nurses' resistance to health technology use is high [5], however their intention to use HEIMS was observed to be encouraging and had significant influence. According to the description of SI from the UTAUT model, "it is peoples' perception about how important they are to the society based on what they do or behave towards achieving their goals in their immediate working environment or surroundings" [13]. Image, social factors and subjective norms are, therefore, the three concepts of SI. The way people act or behave in their immediate environment is basically based on the aforementioned concepts which have substantial influence on what they do or not do. Most of the nurses' adoption of HEIMS were based on these concepts. The BI was significantly influenced by SI to use and adopt HEIMS in Ghanaian hospitals. It is evident from the results (Table 4) that SI had significant influence on the intention of nurses to adopt and use HEIMS. In terms of Pearson's correlation analysis, it was also evident that SI and BI had a positive significant correlation at $p<0.01$ level (Table 5), which means that as the number of nurses with positive intention to use HEIMS increased, the number of nurses being influenced socially also increased. The SI also influenced UB directly towards the use of HEIMS (Table 4). With respect to the Pearson's correlation analysis (Table 5), SI and UB had a positive significant correlation ( $\mathrm{p}<0.01)$, which also means that as SI on nurses increased with increasing UB towards the HEIMS adoption. Therefore, the hypotheses ( $\mathrm{H} 1$ and $\mathrm{H} 2)$ were accepted due to the significant results obtained after the testing. It could be concluded based on these results that most of the nurses' reason that the use of the system will make them attain higher status than their colleagues who do not. It also suggests that the hospitals in Ghana might have encouraged and supported them to adopt HEIMS in the provision of quality healthcare services to their clients. UTAUT model description of FCs is the necessary IT resources to use a system and the technical infrastructure that exists to support this usage as well as the degree to which an individual believes that an organization can provide the necessary knowledge and training for HEIMS. Pertinently, since healthcare providers like nurses are likely to resist technology, there is the need to adequately equip them with technological equipment required for HEIMS usage and good training, else the adoption of any HEIMS could be rejected. The influence of $\mathrm{FC}$ with $\mathrm{BI}$ as the mediator on UB to use and adopt HEIMS was not statistically significant (Table 4 and Fig. 2). The structural model standardized estimates and their probability values are usually known (as $p$-values) showed that FC did not reach statistical significance level. In view of this, the direct influence of FC on UB to use HEIMS hypothesis was rejected. Notwithstanding, FC recorded a strong significant relationship with UB (Table 5) which indicates that when nurses receive adequate training, they will be confident to accept and use new and advanced health technologies in future. The Pearson correlation between FC and BI was statistically significant $(p<0.01)$. From Table 4 , it could be deduced that the results of the structural model of FC showed a significant positive influence on $\mathrm{BI}$ resulting in the acceptance of the hypothesis. The direct influence of BI on UB to use HEIMS was significant (Table 4) with explained $39.6 \%$ of variance associating with UB to use HEIMS. The hypothesis that BI will directly influence UB to use or adopt HEIMS was, therefore, accepted. Wholly, SI explained $43.2 \%$ of the variance associated with UB. Hence, SI, FC and BI all directly explained $51.7 \%$ of the variance associated with usage behavior (Table 6 and Fig. 2).

\section{Limitations}

The outcome of this research is subject to some limitations. Since, the respondents answered questions with respect to their understanding, experiences and perceptions, it is possible that the collected data might not appropriately reflect the objectives of this study. Nonetheless, the

Table 4 Structural Model; Hypothesis Testing Results

\begin{tabular}{|c|c|c|c|c|c|c|c|}
\hline Hypothesis & Parameter & $R^{2}$ & Estimate & S. E & C. $R$ & Significance & Results \\
\hline $\mathrm{H} 1$ & $\mathrm{BI}<---\mathrm{SI}$ & 0.38 & .55 & .04 & 14.06 & $* * *$ & Accepted \\
\hline $\mathrm{H} 2$ & UB $<---S \mid$ & 0.43 & .77 & .07 & 11.76 & $* * *$ & Accepted \\
\hline $\mathrm{H} 3$ & $B \mid<---F C$ & 0.16 & .16 & .03 & 4.80 & $* * *$ & Accepted \\
\hline $\mathrm{H} 4$ & $U B<---F C$ & 0.14 & .07 & .05 & 1.44 & 0.15 & Rejected \\
\hline $\mathrm{H} 5$ & $U B<---B \mid$ & 0.40 & .59 & .06 & 10.22 & $* * *$ & Accepted \\
\hline
\end{tabular}

NB: ***p-value < 0.001, S.E.- Standard Error, C.R. - Critical Ratio, SI - Social Influence, FC - Facilitating Conditions, BI - Behavioural Intention and UB - Use Behaviour. $R^{2}$ - Square root of correlation coefficients of the intercepts 
Table 5 Partial Correlation Matrix of Constructs

\begin{tabular}{|c|c|c|c|c|c|c|c|c|}
\hline Measure & Age & Gender & Prof. Experience & Vol & $\mathrm{SI}$ & FC & $\mathrm{Bl}$ & UB \\
\hline Age & NA & & & & & & & \\
\hline Gender & -.051 & NA & & & & & & \\
\hline Prof. Experience & $.818^{* *}$ & -.043 & NA & & & & & \\
\hline Vol & $.165^{* *}$ & .033 & $-.259^{* *}$ & NA & & & & \\
\hline SI & $.157^{* *}$ & $-.176^{* *}$ & $.162^{* *}$ & $-.244^{* *}$ & 0.796 & & & \\
\hline FC & $.147^{* *}$ & $-.110^{* *}$ & $.143^{* *}$ & .008 & $.448^{* *}$ & 0.739 & & \\
\hline $\mathrm{Bl}$ & $.135^{* *}$ & $-.217^{* *}$ & $.184^{* *}$ & $-.219^{* *}$ & $.612^{* *}$ & $.399^{* *}$ & 0.972 & \\
\hline UB & $.200^{* *}$ & $-.159^{* *}$ & $.264^{* *}$ & $-.316^{* *}$ & $.657^{* *}$ & $.375^{* *}$ & $.630^{* *}$ & 0.949 \\
\hline
\end{tabular}

NB: **Correlation is significant at $p$-values $<0.01$, the bold values on the leading diagonal show the discriminant validity (DV) of the constructs and the nondiagonal values are the correlation coefficients between the constructs. SI - Social Influence, FC - Facilitating Conditions, BI - Behavioural Intention, $\boldsymbol{U} \boldsymbol{B}$ - Use Behaviour, Vol - Voluntariness

quality of the data collected is satisfactory with regards to the nature of the report. Besides, the subjects were voluntarily recruited for this survey, albeit the believe that this did not negatively affect the findings since this approach has been usually employed in this field [29].

\section{Conclusions}

The application of the research model demonstrated that nurses' adoption of HEIMS in terms of the UB was influenced by SI and BI. Besides, SI and FC had the strongest influence on BI (serving as mediator) of UB to adopt and use HEIMS among the nurses in Ghanaian hospitals. Based on these findings, hospital administrators should put measures in place to ensure a conducive working environment for the nurses to continue using HEIMS as well as encourage and support them to adopt and use the system. Hospital managers should also continue to provide the necessary IT resources needed to use the HEIMS. These study results provide empirical and scientific contributions to aid better understanding of the behavioral

Table 6 Explained Variance of Constructs

\begin{tabular}{|c|c|c|c|}
\hline \multicolumn{2}{|c|}{ Independent Variables (IV) } & \multirow{2}{*}{$\begin{array}{l}\text { Dependent } \\
\text { Variables } \\
\text { (DV) }\end{array}$} & \multirow{2}{*}{$\begin{array}{l}\text { R- } \\
\text { squared } \\
\left(R^{2}\right)\end{array}$} \\
\hline Constructs & Moderators & & \\
\hline$\overline{\mathrm{SI}}$ & no & $\mathrm{Bl}$ & 0.375 \\
\hline $\mathrm{SI}$ & age, gender, prof. Exp. \& Vol. & & 0.401 \\
\hline FC & no & & 0.160 \\
\hline FC & age, gender, prof. Exp. \& Vol. & & 0.248 \\
\hline SI \& FC & age, gender, prof. Exp. \& Vol. & & 0.421 \\
\hline $\mathrm{SI}$ & na & UB & 0.432 \\
\hline FC & na & & 0.140 \\
\hline $\mathrm{Bl}$ & na & & 0.396 \\
\hline $\mathrm{SI}, \mathrm{FC} \& \mathrm{BI}$ & na & & 0.517 \\
\hline
\end{tabular}

$R^{2}$ is the amount of variance in the dependent variable (DV) that is accounted for or explained by the independent variable(s) (IV). BI - Behavioural Intention, UB Use Behaviour, SI - Social Influence and FC - Facilitating Conditions. na - not applicable, Vol - Voluntariness issues regarding the readiness of nurses in the adoption of HEIMS in Ghanaian Hospitals. The outcome of this study will enrich the literature in this area and create an important awareness which will initiate further research, especially in developing countries.

\begin{abstract}
Abbreviations
BI: Behavioral Intentions; FC: Facilitating Conditions; HAMS: Hospital Administration Management System; HEIMS: Hospital Electronic Information Management Systems; HERs: Electronic Health Records; HITs: Health Information Technologies; LHIMS: Lightwave Health Information Management System; SEM: Structural Equation Modelling; SI: Social influence; SPSS: Statistical Package for the Social Sciences; UB: Use Behavior; UTAUT: Unified Theory of Acceptance and Use of Technology
\end{abstract}

\section{Acknowledgements}

We would like to thank all the Nurses who avail themselves for the success of this study. We would like to also thank the National Natural Science Foundation of China, Postdoctoral Foundation of China, and the Postdoctoral Foundation of Jiangsu Province.

\section{Authors contribution}

Professor LLZ and JOM conceived and designed this study. Professor LLZ is the overall supervisor of the research team. JOM designed the electronic form of the questionnaire in the open data kit (ODK) platform to be uploaded to the android platform smart mobile phones. JOM, MOA, ADTK and SAW contributed to the writing of this manuscript from literature searching, data collection, analysis and the final write up. HAA contributed to the write-up and editing of this paper. All authors read and approved the final manuscript

\section{Funding}

This work was supported by the National Natural Science Foundation of China (Grants nos. 71974079) during the design of the study and data collection period.

\section{Availability of data and materials}

The datasets used and/or analysed during the current study are available from the corresponding author on reasonable request.

\section{Ethics approval and consent to participate}

This study was approved by the Ghana health service research ethical committee (No. GHS-ERC:05-12-18). The Health facility Directors/Managers also gave approval before data were collected. All the participants were contacted during their working shifts and invited verbally to participate in this survey. An informed consent form (signed) was obtained from those who agreed to take part in the study. The participants were guaranteed response anonymity. 


\section{Consent for publication}

Not applicable.

\section{Competing interests}

The authors declare that there are no competing interests regarding the publication of this paper.

Received: 28 May 2019 Accepted: 31 October 2019

Published online: 21 November 2019

\section{References}

1. A. J. Buabbas, P. Sharma, A. Al-Abdulrazaq, and H. Shehab, "Smartphone use by government dermatology practitioners in Kuwait: a self-reported questionnaire based cross-sectional study," BMC Med. Inform. Decis. Mak. vol. 19, no. 155, 2019.

2. Maillet É, Mathieu L, Sicotte C. Modeling factors explaining the acceptance, actual use and satisfaction of nurses using an electronic patient record in acute care settings: an extension of the UTAUT. Int J Med Inform. 2015; 84(1):36-47.

3. Hsiao J-L, Chang H-C, Chen R-F. A study of factors affecting acceptance of hospital information systems. J Nurs Res. 2011;19(2):150-60.

4. A. Mervat and A. H. Mary, Health information (Management of a Strategic Resource. Elsevier, 2016.

5. H. Alquraini, A. M. Alhashem, M. a Shah, and R. I. Chowdhury, "Factors influencing nurses' attitudes towards the use of computerized health information systems in Kuwaiti hospitals," J Adv Nurs, vol. 57, pp. 375-381, 2007.

6. Vélez O, Okyere PB, Kanter AS, Bakken S. A usability study of a mobile health application for rural Ghanaian midwives. J Midwifery Women's Heal. 2014; 59(2):184-91.

7. Venkatesh V, Morris MG, Davis GB, Davis FD. User acceptance of information technology: toward a unified view. MIS Q. 2003;27(3):425-78.

8. N. Mensah et al., "Impact of an electronic clinical decision support system on workflow in antenatal care: The QUALMAT eCDSS in rural health care facilities in Ghana and Tanzania," Glob. Health Action, vol. 8, no. 1, 2015.

9. Wu IL, Li JY, Fu CY. The adoption of mobile healthcare by hospital's professionals: an integrative perspective. Decis Support Syst. 2011:51(3):587-96.

10. Melas CD, Zampetakis LA, Dimopoulou A, Moustakis V. Modeling the acceptance of clinical information systems among hospital medical staff: an extended TAM model. J Biomed Inform. 2011;44(4):553-64.

11. Ketikidis P, Dimitrovski T, Lazuras L, Bath PA. Acceptance of health information technology in health professionals: an application of the revised technology acceptance model. Health Informatics J. 2012;18(2):124-34.

12. Ahlan AR, Ahmad BI. User acceptance of health information technology (HIT) in developing countries: a conceptual model. Procedia Technol. 2014 16:1287-96

13. V. Venkatesh and X. Zhang, "Unified Theory of Acceptance and Use of Technology: U . S. Vs. China," J Glob Inf Technol Manag, vol. 13, no. 1, pp. 5-27, 2010.

14. Guillemin F, Bombardier C, Beaton D. Cross-cultural adaptation of healthrelated quality of life measures: literature review and proposed guidelines. J Clio Epidemiol. 1993;46(12):1417-32.

15. Wright G, O'Mahony D, Kabuya C, Betts H, Odama A. Nurses behaviour pre and post the implementation of data capture using tablet computers in a rural clinic in South Africa. Eur Fed Med Informatics. 2015;210:803-7.

16. Gefen D, Straub DW, Boudreau M-C. Structural equation modeling and regression : guidelines for research practice. Commun Assoc Inf Syst. 2000;4:1-79.

17. Haenlein M, Kaplan A. A beginner's guide to partial least squares analysis. Taylor Fr. 2004:3(4):283-97.

18. Chin WW, Marcolin BL, Newsted PR. A partial least squares latent variable modeling approach for measuring interaction effects: results from a Monte Carlo simulation study and an electronic-mail emotion/ adoption study. Inf Syst Res. 2003;14(2):189-217.

19. Vinzi VE, Trinchera L, Amato S. Handbook of partial least squares; 2010

20. Straub D, Boudreau M-C, Gefen D. Validation guidelines for IS positivist research. Commun Assoc Inf Syst. 2004;13(24):380-427.

21. Gefen D, Straub D. A practical guide to factorial validity using PLS-graph: tutorial and annotated example. Commun Assoc Inf Syst. 2005:16:91-109.

22. Abdalla Mohammed T, Muhammed Pandhiani S. Analysis of factors affecting student evaluation of teaching effectiveness in Saudi higher education: the case of Jubail University college. Am J Educ Res. 2017;5(5):464-75.
23. R. P. Bagozzi, "Evaluating structural equation models with unobservable variables and measure ...," J Mark Res, vol. 18, no. 1, pp. 39-50, 1986.

24. Mateos-Aparacio G. Partial least squares (PLS) methods: origins, evolution, and application to social sciences. Commun Stat Methods. 2011:40(13):1-18.

25. M. Wills, O. El-Gayar, and D. Benett, "Examining Healthcare Professionals ' Acceptance of Electronic Medical Records Using Utaut," Issues Inf. Syst., vol. IX, no. 2, pp. 396-401, 2008.

26. J. H. Schuenemeyer, "Multivariate Statistical Modelling and Data Analysis," in Technometrics, 6th editio., vol. 31, no. 3, NJ: Prentice Hall, 1989.

27. Chen RF, Hsiao JL. An investigation on physicians' acceptance of hospital information systems: a case study. Int J Med Inform. 2012;81(12):810-20.

28. Fornell C, Larcker DF. Evaluating structural equation models with unobserved variables and measurement error. J Mark Res. 1981;18(1):39-50.

29. Yontz LS, Zinn JL, Schumacher EJ. Perioperative nurses' attitudes toward the electronic health record. J Perianesthesia Nurs. 2015:30(1):23-32.

\section{Publisher's Note}

Springer Nature remains neutral with regard to jurisdictional claims in published maps and institutional affiliations.

Ready to submit your research? Choose BMC and benefit from:

- fast, convenient online submission

- thorough peer review by experienced researchers in your field

- rapid publication on acceptance

- support for research data, including large and complex data types

- gold Open Access which fosters wider collaboration and increased citations

- maximum visibility for your research: over $100 \mathrm{M}$ website views per year

At $\mathrm{BMC}$, research is always in progress.

Learn more biomedcentral.com/submissions 